\title{
RELIABILITY AND CONCURRENT VALIDITY OF Visual Analogue Scale and Modified Verbal Rating ScAle of PAIN Assessment in Adult PATIENTS WITH KNEE OSTEOARTHRITIS IN Nigeria
}

\begin{abstract}
The objective of this study was to determine the reliability and concurrent validity of two pain rating scales - Visual Analogue Scale (VAS) and Verbal Rating Scale (VRS). The verbal rating scale was modified by translating the English description of subjective pain experience into vernacular (Yoruba) equivalents and rating the knee pain when the patient was standing with the knee flexed.
\end{abstract}

Twenty seven patients who were clinically and radiologically diagnosed with osteoarthritis $(O A)$ and with knee pain were purposively selected for the study.

Two testers (physiotherapists) independently rated the pain experienced by patients, when bearing full weight while standing on the affected leg with slight knee flexion, over a period of several days. For each patient pain was rated with the VAS and the modified VRS (MVRS).

There were significant correlations between VAS and MVRS by the same tester (tester 1 and tester2) $(r=0.92$, $p<0.01 ; r=0.89, p<0.01$ respectively, )) and between VAS and MVRS between tester 1 and tester $2(r=0.91, p<0.01)$. There were no significant differences between VAS for tester 1 and VAS for tester 2, and between MVRS for tester 1 and MVRS for tester $2(p>0.01)$.

According to this study, the two pain rating scales for knee OA are reliable. Our use of VAS and MVRS together with the procedure involving the flexed knee posture is, therefore, recommended for wider clinical trials.

\section{KEY WORDS: PAIN RATING, KNEE OSTEOARTHRITIS}

\section{INTRODUCTION}

According to the International Association for the Study of Pain, pain is defined as an unpleasant and emotional experience associated with actual or potential tissue damage, or described in terms of such damage (Readyard and Edwards, 1992). Pain is differentiated from other sensations by characteristic expressions. Pain can also be described as being a highly subjective experience, and response to noxious stimuli may be modified by psychological factors such as state of mind, past experience and conditioning influences, as well as sociological factors such as gender and culture (French, 1989). Physically pain could be a burn, toothache, inflammation, migraine etc. Psychologically it

CORRESPONDENCE TO:

M.O.B. Olaogun

Email:mobolaogun@yahoo.co.uk could be the loss of a precious item, or witnessing the suffering of another person. Budd (1996) classified physical pain according to causes viz: nociceptive (stimulation of nociceptors) neurogenic (malfunction or damage to nervous tissues) sympathogenic (malfunction of the sympathetic arm of the autonomic system) and visceral pain (prolonged noxious stimulation of high threshold receptors, intensity encoding receptors and silent nociceptors).

The mechanism of pain production in OA of the knee suggests that the cause is physical and can be a combination of nociceptive and neurogenic type. There are no receptor nerve endings in the articular cartilage synovium or menisci (Baldry,1993). Pain, therefore, can not arise directly from the cartilage itself. Subchondrial bone is however well supplied with nerves. Following the denudation of the cartilage, in the early stage of the disease, it is conceivable that in the absence of adequate protection by the articular cartilage, subchondrial tissue at the articulating ends of the tibia and femur and at the posterior surface of the patella are open to irritations by compressive forces. Mechanical irritation of such nerves may generate pain. There are also nociceptive receptors in the individual sheaths of the vessel in the wall of the synovial sac. According to Baldry (1993) and Shipton (2000) pain can also occur as a result of the effect of chemical substances such as 5-Hydroxytryptamine, prostaglandin, histamine and polypeptides released from inflamed synovial cells and carried in the synovial fluid to the adjacent articular fat pad and articular joint capsule where they have irritant effect on the nociceptive receptors. It behoves the clinician to understand the possible mechanism of pain production in OA before attempting to assess the intensity and to plan the rehabilitation of the pain. 
The main reasons for assessing pain in rehabilitative management of symptomatic osteoarthritis of the knee are to assist in establishing a baseline, to select appropriate interventions and to evaluate the patients response to treatment and rehabilitative management. Since pain is localized to the individual, assessment may be difficult as it is subjective to patient's understanding, cooperation, functional status and response. Behavioural and subjective approaches adopted by some recent authors have therefore offered reliable tools for clinical assessment of pain (Borg, 1982, Briggs,1999, Finch and Melzack, 1987, Olaogun et. al, 2001, Varni et. al, 1987). Such approaches include the Verbal Rating Scale (VRS) and the Visual Analogue Scale (VAS) (Readyard and Edwards, 1992) - see table 1. This present study aims at determining the inter and intra -tester reliability and concurrent validity of VAS and modified VRS (MVRS) in an indigenous environment without bias for gender and literacy level. VRS was modified by translating the English descriptions of subjective pain experience into Yoruba, the dominant indigenous language in the locality of the study. Reference was made to similar translations by Akinpelu and Olowe (2000) for rating physical function and physical performance. Furthermore, for the purpose of uniqueness and clinical application, a condition that can be easily diagnosed and characterized by physical pain was chosen - osteoarthritis (OA) of the knee. It was hypothesized that

(i) there will be no significant correlation between MVRS and VAS by the same tester (tester 1 or tester 2),

(ii) there will be no significant correlation in MVRS and VAS between testers;

(iii) there will be no significant difference in MVRS between testers and

(iv) there will be no significant difference in VAS between testers.

\section{METHOD}

\section{Subjects}

Twenty-seven patients clinically and radiologically diagnosed with OA with knee pain were purposively selected for this study. Patients were selected follow-

Table 1:

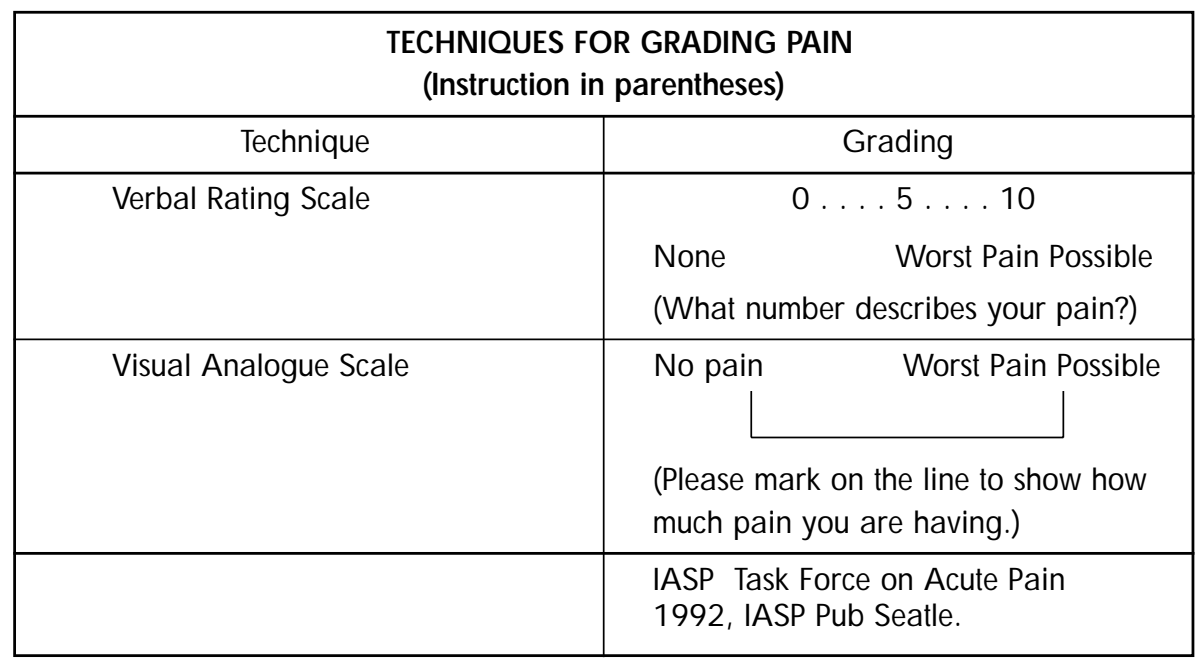

Table 2:

\begin{tabular}{|l|ll|}
\hline \multicolumn{3}{|c|}{ MO DIFIED VERBAL RATIN G SCALE (in Flexed Knee Position) } \\
\hline English & Yoruba & \\
\hline N o pain & Kosi irora rara & \\
Barely Perceptible pain & Irora ti ko lonkan lati furasi & 2 \\
Mild Pain & Irora to se faramo & 4 \\
Moderate Pain & Irora ni won ba & \\
Barely Strong Pain & Irora to po die & \\
Strong/ Severe Pain & Irora to le & 8 \\
Intense Pain & Irora to po \\
Very Intense Pain & Irora to po lopolopo \\
Horrible (most uncomfortable) Pain & Irora to lini lara \\
Worst (Excrutiating) Pain & Irora to pojulo (to le payan) & 10 \\
\hline \multicolumn{2}{|c|}{ (Mark the one that corresponds to the pain you feel at this moment) } \\
\hline
\end{tabular}

ing the criteria of Altman (1986):

- Patients presented with knee pain and radiographic osteophytes

- Age equal to or greater than 40 years

- Morning stiffness less than or equal to 30 minutes duration

- Crepitus on motion

\section{Instrumentation}

For this study a questionnaire consisting of two sections, $\mathrm{A}$ and $\mathrm{B}$, were used. A contained the demographic data of subjects. Section B contained the Visual Analogue Scale and Modified Verbal Rating Scales for two Testers - refer to tables 1 and 2.

\section{Pilot w ork}

Two physiotherapists with clinical experience of 5 and 8 years were recruited as testers (tester 1 and tester 2). Two practice sessions were arranged during which the testers and the principal researcher agreed on the position to be adopted while rating the pain experience. Seven patients were used. Patients were asked to describe when pain was experienced in these movements - free walking, ascending stairs and descending stairs. In four it was during midstance phase while walking and in three it was when descending stairs with the affected leg leading in a forward downward leading (FDL) stepping manoeuvre; but all experienced greatest pain when climbing stairs with Forward Upward Leading (FUL) stepping manoeuver, (Olaogun et. al, 1989). It was then agreed that pain would be rated with the patient bearing full weight while standing on the affected leg with slight knee flexion. This adopted position is similar to that of the painful phase of FUL as shown in figures I and 2. 
Figure 1: Patient in Forward Upward Stepping Movement with the Right Leg

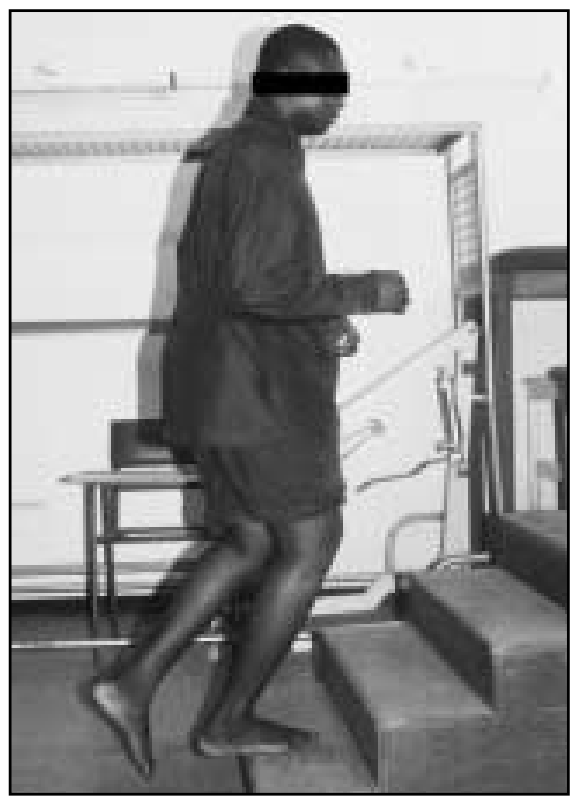

Figure 2: Patient in Full Weight Bearing on Right Leg with Slight Knee Flexion

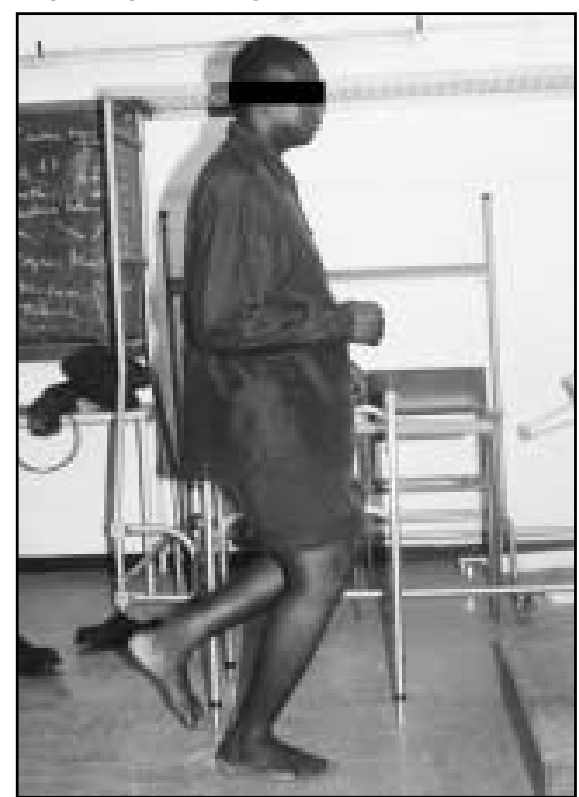

Table 3: Ranges, Means and Standard Deviations of Anthropometric Characteristics $(\mathrm{N}=\mathbf{2 7})$

\begin{tabular}{|l|l|l|l|l|}
\hline & $\begin{array}{l}\text { Range } \\
\text { Minimum }\end{array}$ & Maximum & Mean & SD $( \pm)$ \\
\hline W eight $(\mathrm{kg})$ & 60 & 89 & 72.4 & 8.6 \\
\hline Height $(\mathrm{m})$ & 1.25 & 1.90 & 1.61 & .16 \\
\hline BMI & 22.37 & 39.68 & 28.36 & 4.1 \\
\hline
\end{tabular}

Legend:

SD: Standard Deviation (t)

BM I: Body Mass Index (W eight $(\mathrm{kg}) /$ Height(m)2)

Table 4: Correlation Matrix of OA Pain ratings with Visual Analogue Scale and with Modified Verbal Rating Scale.

\begin{tabular}{|l|l|l|l|l|}
\hline \multicolumn{5}{|l|}{ Test of Intra and Inter tester agreement. } \\
\hline & VAS1 & VAS2 & MVRS1 & MVRS2 \\
\hline VAS1 & 1 & & & \\
\hline VAS2 & .959 & 1 & & \\
\hline MVRS1 & .922 & .909 & 1 & \\
\hline MVRS2 & .989 & .892 & .934 & 1 \\
\hline
\end{tabular}

Legend:

VAS - Visual A nalogue scale

VRS - Verbal Rating Scale

VAS1 - Pain Rating with VAS by Tester 1

VAS2 - Pain Rating with VAS by Tester 2

MVRS - Pain Rating with MVRS by Tester 1

MVRS2 - Pain Rating with MVRS by tester 2

\section{Experimental design}

Two ratings using the VAS and modified MVRS were taken by testers for the same patients on the same days. Ratings for the patients were taken across several of the first rating scale to be used was randomized. The two testers were prevented access to the raw data with the principal researcher during the data collection phase.

\section{Procedure}

Pain rating was taken in a testing cubicle. The other tester was not allowed to be in the testing cubicle whenever the other tester took measurement. Patient was asked to stand on the more painful knee and flex the knee slightly. The tester administered the two rating scales separately. The principal investigator was in the testing room to monitor and record the measurement.

\section{STATISTICAL ANALYSIS}

Descriptive and inferential statistics were used for the analysis of the data. Mean values of age, height, weight and BMI were obtained. Mean values of pain ratings for VAS and MVRS were obtained.

With the aid of SPSS computer programme Pearson Product Movement Correlation Coefficients were computed to compare intra-tester agreements of the two scales and inter-tester agreements of the testers. T-test was invoked to compare inter-tester ratings of the two scales. A $1 \%$ level of probability was used.

\section{RESULTS}

The mean, range and standard deviations (SD) of the patients' physical characteristics are shown in Table 3. The mean BMI of 28.36 and low SD of \pm 4.1 indicated that the patients sample was fairly homogenous with tendency to overweight.

Table 4 shows intra-tester and inter tester correlation matrix for VAS and MVRS for testers (intra) and for VAS between testers and MVRS between testers. There was a strong intra-tester correlation between VAS and MVRS and strong inter-tester correlation for VAS and MVRS. For tester 1 correlation co-efficient (r) was 0.92 for VAS vs MVRS $(\mathrm{P}<0.01)$. For tester $2 \mathrm{r}$-value was 0.892 for VAS vs. MVRS ( $\mathrm{P}<0.01)$. For inter-tester correlation r-value was 0.909 for MVRS and (0.959) for VAS $(\mathrm{p}<0.01)$. 
Table 5: Interater Reliability of VAS and MVRS Pain Rating

\begin{tabular}{|c|c|c|c|c|c|c|c|c|}
\hline \multicolumn{9}{|l|}{ Paired T-Test } \\
\hline & Mean & $\begin{array}{l}\text { Std } \\
\text { Deviation }\end{array}$ & $\begin{array}{l}\text { Std } \\
\text { Error Mean }\end{array}$ & $\begin{array}{l}\text { 95\% Confid } \\
\text { Interval of } \\
\text { Difference } \\
\text { Lower }\end{array}$ & $\begin{array}{l}\text { nce } \\
\text { Upper }\end{array}$ & $\mathbf{t}$ & df & $\begin{array}{l}\text { Sig } \\
\text { (2-tailed }\end{array}$ \\
\hline $\begin{array}{l}\text { Pair1 } \\
\text { VAS1-VAS2 }\end{array}$ & .1333 & .4057 & $7.808 \mathrm{E}-02$ & $-2.72 \mathrm{E}-02$ & .2938 & 1.708 & 26 & $.100 \mathrm{NS}$ \\
\hline $\begin{array}{l}\text { Pair2 } \\
\text { M VRS1-MVRS2 }\end{array}$ & $-3.70 \mathrm{E}-02$ & 1.3723 & .2641 & -.5799 & .5058 & -.140 & 26 & $.890 \mathrm{NS}$ \\
\hline
\end{tabular}

NS $=\mathrm{N}$ ot significant

$\mathrm{P}>01$

The result of t-test in Table 5 shows that there was no significant difference between pain rating with VAS for tester 1 and with VAS for tester $2(\mathrm{P}>0.01)$. Similarly, there was no significant difference between pain rating with MVRS for tester 1 and with MVRS for tester 2 ( $\mathrm{P}>0.01)$.

\section{DISCUSSION}

The results of this study showed that there was no significant difference in mean scores obtained in the VAS conducted by the two testers $(\mathrm{P}>0.01)$; and in MVRS by the two testers ( $\mathrm{P}>0.01$ ) on patients with symptomatic pain of knee OA. Our hypothesis that there will be no significant difference between MVRS for tester1 and MVRS for tester 2 is therefore accepted. Similarly our hypothesis that there will be no significance difference between VAS for tester 1 and VAS for tester 2 is also accepted. There were, however, significant correlations between scores of patients on VAS and MVRS for tester 1 and for tester 2. Our first and second hypotheses that there will be no significant correlations are therefore rejected. Our findings support the previous work by Briggs (1999). He reported good correlations between VAS and VRS in rating post-operative pain.

Other pain rating procedures like McGill Pain Questionaire (MPQ) (Finch and Melzack, 1987) may not be easily understood in low literacy setting like that of this study. In their study to identify the most common sites of pain in symptomatic knee osteoarthritis, Creamer et al (1998) found that knee pain is not the same with respect to location in all individuals. This indicated the heterogeneity of the condition. This observation was noted in our pilot study. But since the pain differed much with respect to weight bearing on the affected knee our approach in asking our subject to bear weight and slightly flex the knee generalizes functional location of pain by combining patellofemoral and tibiofemoral involvement. In other words the flexed knee position compromises compressive forces at the patello femoral and tibio femoral joints for all the patients. Further studies will however be recommended to limit the heterogeneity of pain location for better results in assessing pain in knee ostoearthritis.

\section{CONCLUSION}

Overall our study concludes that the two methods of pain rating are reliable and valid for clinical use. Our use of VAS and MVRS together with the flexed knee procedure is, therefore, suggested for wider clinical trials in assessing the outcome measure of pain modulation in the rehabilitative management of symptomatic osteoarthritis of the knee.

\section{REFERENCES}

Altman R 1986 Development of criteria for the classification and reporting of osteoarthritis. Arthritis Rheumatology 29: 1030-1044

Akinpelu AO, Olowe OO 2000 Physical functions and physical performances in patients with pain. Presentation at the 3rd Annual Conference of the Society for the Study of Pain, Ibadan, Nigeria. 27th- 28th July, 2000

Baldry P 1993 Acupuncture. Trigger Points and Musculoskeletal Pain.5th edn pp130-135. Churchhill Livingstone, Edinburg
Borg GAV 1982 Psychological Bases of Perceived Exertion, Medicine and Science in Sports and Exercise, 14:377-381.

Briggs M 1999 A Descriptive Study of VAS and VRS for the assessment of post operative pain in Orthopaedic patients, Journal of Pain Symptom Management, 18 (6), 438-446

Budd K 1996 Chronic Pain and its Treatment. Therapy Express No.106, Dec., P.4

Creamer P, Lethbridg-Cejku M, Hochberg MC 1998 Determinants of Pain Severity in Knee Osteoarthritis: Effect of Demographic and Psychological variables using 3 pain measures. J. Rheumatology 1999 Aug. 26 (8): 1785-92

Finch L, Melzack R 1987 Objective Pain Measurement, a case for increased clinical usage, Physiotherapy Canada, 34 (6): 343-345

French S 1989 Some Physiological and Sociological aspects of pain: Physiotherapy; 75:255-259

Olaogun MOB, Abereoje OK, Obajuluwa VA 1989 Step Test for Clinical Evaluation of Locomotor Ability. Clinical Rehabilitation, 3, 41-45

Olaogun MOB, Fagade OO, Akinloye AA, Omojolowo O 2001 Effects of TENS on Pain, Swelling and Trismus following Third Molar Tooth Extraction, Nig. Jour. Health Sci., (1); $18-21$

Readyard LB, Edwards WT 1992 Management of Acute Pain. A Practical Guide, I.A.S.P. Publication, Seattle, Pg.2.

Shipton EA 2000 Pain in the New Millenium. The First African Congress on Pain - Pain Free Africa. Alexandra, Egypt; Abstract Book: pp.107-124

Varni JW, Thompson KL, Hanson V 1987 The Varni-Thompson Pain Questionnaire Constructed for the Dutch Language (MPQ-DU). Pain; 30:395-408 